IANCU (Carol), La Shoah en Roumanie. Les Juifs sous le régime d'Antonescu (1940-1944). Documents

diplomatiques français inédits

Montpellier, Université Paul-Valéry Montpellier III, 1998, 189 p. (cartes)

(coll. «Sem-Études juives et hébraïques » $\mathrm{n}^{\circ} 7$ )

Yves Chevalier

\title{
OpenEdition
}

Journals

Édition électronique

URL : http://journals.openedition.org/assr/20655

DOI : 10.4000/assr.20655

ISSN : $1777-5825$

Éditeur

Éditions de l'EHESS

Édition imprimée

Date de publication : 1 juillet 2000

Pagination : 119

ISBN : 2-222-96691-4

ISSN : 0335-5985

Référence électronique

Yves Chevalier, «IANCU (Carol), La Shoah en Roumanie. Les Juifs sous le régime d'Antonescu

(1940-1944). Documents diplomatiques français inédits ", Archives de sciences sociales des religions [En ligne], 110 | avril-juin 2000, document 110-68, mis en ligne le 19 août 2009, consulté le 21 septembre 2020. URL : http://journals.openedition.org/assr/20655; DOI : https://doi.org/10.4000/assr.20655

Ce document a été généré automatiquement le 21 septembre 2020.

(c) Archives de sciences sociales des religions 


\section{IANCU (Carol), La Shoah en Roumanie. Les Juifs sous le régime d'Antonescu (1940-1944). Documents diplomatiques français inédits}

Montpellier, Université Paul-Valéry Montpellier III, 1998, 189 p. (cartes) (coll. «Sem-Études juives et hébraïques » $\mathrm{n}^{\circ} 7$ )

Yves Chevalier

\section{RÉFÉRENCE}

IANCU (Carol), La Shoah en Roumanie. Les Juifs sous le régime d'Antonescu (1940-1944). Documents diplomatiques français inédits, Montpellier, Université Paul-Valéry Montpellier III, 1998, 189 p. (cartes) (coll. « Sem-Études juives et hébraïques » nº 7)

1 L'auteur, professeur d'histoire contemporaine à l'Université Paul-Valéry, s'est donné entre autres pour tâche de présenter la situation des juifs de Roumanie depuis le milieu $\mathrm{du}$ siècle dernier. Il l'a fait d'abord dans une thèse de $3^{\mathrm{e}}$ cycle, en étudiant l'évolution de la minorité juive de 1866 à 1919 et son combat pour une intégration complète dans la société roumaine. Intégration fragile, parce que le processus d'émancipation fut partiellement initié de l'extérieur par les Grandes Puissances, notamment à l'occasion du Congrès de Berlin en 1878 et de la signature du Traité de Saint-Germain-en-Laye en 1919 (De l'exclusion à l'émancipation, Éditions de l'Université de Provence, 1978. : cf. Arch., $\mathrm{n}^{\circ}$ 48-428). Il étudia ensuite, dans sa thèse de Doctorat d'État, « l'évolution du statut juridique et politique des Juifs de Roumanie » entre 1913 et 1938 (De l'émancipation à la marginalisation, Peeters, 1996) marquée par les difficultés d'une reconnaissance pleine et entière dans un contexte d'antisémitisme d'abord plus ou moins officiel - et qui devint un "antisémitisme d'état» durant la décennie trente. Il était de ce fait intéressant de poursuivre l'enquête afin de dresser l'inventaire de la politique antijuive 
et de «purification ethnique » du régime du dictateur Antonescu (14 septembre 1940-23 août 1944).

Pour ce faire, l'A. a sélectionné dans les archives du ministère français des Affaires étrangères, cent documents diplomatiques inédits - télégrammes, lettres, rapports émanant essentiellement des représentants de la France à Bucarest (Ambassade d'abord, ensuite Légation). Ces documents permettent de mettre en lumière la situation de plus en plus difficile des juifs de Grande Roumanie - y compris ceux de la Transylvanie du Nord - au fur et à mesure que la législation antisémite se développe, que les effets des spoliations et de la «roumanisation » se font de plus en plus sentir. Même s'il s'est agi d'une "Shoah inachevée ", pour reprendre l'expression même de l'A., c'est-à-dire sans chambre à gaz, il n'en reste pas moins que la période fut tragique : les sévices infligés à la population juive, les pogroms, les déportations et les massacres même si ces deux derniers furent stoppés par Antonescu pendant l'été 1942 - eurent pour résultats de faire disparaitre plus de 375000 juifs, sur une population évaluée à 750000 (soit $49 \%$ ).

Dans une longue introduction-présentation en trois chapitres (pp. 11-47), l'A. rappelle la nature de l'antisémitisme de la Garde de fer entre les deux guerres et l'attitude plus que conciliante du gouvernement, puis décrit son paroxysme au moment de la guerre et précise le contexte dans lequel a été élaborée cette correspondance diplomatique. Et il note que " contrairement aux directives de Vichy, les représentants de la France en Roumanie ont systématiquement refusé de donner suite aux demandes des autorités roumaines concernant la délivrance de certificats ethniques qui auraient permis l'application des discriminations frappant les juifs roumains aux ressortissants français (et d'autres nationalités) d'origine juive.» 